\title{
Comparative evaluation of virtual reality distraction and counter-stimulation on dental anxiety and pain perception in children
}

\author{
Mahesh Nunna', Rupak Kumar Dasaraju², Rekhalakshmi Kamatham', Sreekanth Kumar Mallineni, ${ }^{1,3}$, \\ Sivakumar Nuvvula \\ 'Department of Paedodontics and Preventive Dentistry, Narayana Dental College, Nellore, India \\ ${ }^{2}$ Department of Paedodontics and Preventive Dentistry, Priyadarshini Dental College and Hospital, Thiruvallur, India \\ ${ }^{3}$ Pediatric Dentistry, Preventive Dental Science, College of Dentistry, Majmaah University, Kingdom of Saudi Arabia
}

\begin{abstract}
Background: This study evaluated the efficacy of virtual reality (VR) distraction and counter-stimulation (CS) on dental anxiety and pain perception to local anesthesia in children.

Methods: A prospective, randomized, single-blinded interventional clinical trial with a parallel design was used. Seventy children 7-11 years old who required local anesthesia (LA) for pulp therapy or tooth extraction were recruited and allocated to two groups with equal distribution based on the intervention. Group CS ( $\mathrm{n}=35$ ) received CS and Group VR $(\mathrm{n}=35)$ received VR distraction with ANTVR glasses. Anxiety levels (using pulse rate) were evaluated before, during, and after administration of local anesthesia, while pain perception was assessed immediately after the injection. Wong-Baker faces pain-rating scale (WBFPS), visual analog scale (VAS), and Venham's clinical anxiety rating scale (VCARS) were used for pain evaluation. Student's t-test was used to test the mean difference between groups, and repeated measures ANOVA was used to test the mean difference of pulse rates.

Results: Significant differences in mean pulse rates were observed in both groups, while children in the VR group had a higher reduction $(\mathrm{P}<0.05)$, and the mean VCARS scores were significant in the VR group $(\mathrm{P}$ $<0.05$ ). Mean WBFPS scores showed less pain perception to LA needle prick in the CS group while the same change was observed in the VR group with VAS scores.

Conclusions: VR distraction is better than CS for reducing anxiety to injection in children undergoing extraction and pulpectomy.
\end{abstract}

Keywords: Counter-Stimulation; Dental Anxiety; Distraction; Pain Perception; Virtual Reality.

This is an Open Access article distributed under the terms of the Creative Commons Attribution Non-Commercial License (http://creativecommons.org/licenses/by-nc/4.0/) which permits unrestricted non-commercial use, distribution, and reproduction in any medium, provided the original work is properly cited.

\section{INTRODUCTION}

Pain is an unpleasant sensory and emotional experience associated with actual or potential tissue damage or described regarding such damage, according to the International Association for the Study of Pain [1]. In dentistry, untreated carious teeth involving the pulp are the primary cause of pain in adults and children [2]. To alleviate this pain and to successfully perform the treatment, local anesthesia (LA) administration is a widely used method, which also frequently triggers fear and anxiety in patients [3]. Dental fear is a usually unpleasant emotional reaction to specific frightening

Received: June 10, 2019 • Revised: August 26, 2019 - Accepted: September 9, 2019

Corresponding Author: Dr. Sreekanth Kumar Mallineni MDS, FICD, Associate Professor, Department of Paedodontics and Preventive Dentistry, Narayana Dental College and Hospital, Nellore- 524003, AP, India

Tel: +91-8522900000 E-mail: drmallineni@gmail.com; s.mallineni@mu.edu.sa

Copyright(c) 2019 Journal of Dental Anesthesia and Pain Medicine 
stimuli occurring in the dental operatory [4]. Fear of needles is common in children, which makes them apprehensive during their first dental visit [5]. Fear of pain influences a child during the procedure, which may result in nervousness, sensitization, and uncooperative behavior during the present and future dental appointments [6].

Corah et al. stated that dental anxiety is the patient's response to stress specific to the dental visit [7]. It is a non-specific feeling of apprehension, worry, uneasiness, or dread, the source of which may be unknown [8] and stands fifth among all the feared situations [9]. Anxiety and fear of dental procedures develop in early childhood [4]. According to Rachman's three pathways theory, conditioning (direct response), modeling, and information (indirect responses) are the factors inducing dental anxiety in children [10]. Negative expectations for dental treatment and insufficient child-dentist rapport are cognitive reasons that increase dental anxiety versus non-cognitive factors like fear of the unknown and vicarious learning [11]. Hmud identified factors for dental anxiety in children as $4 \mathrm{~S}$ - Sights (e.g., feeling of worry, uneasiness), Sounds (drilling), Sensations (high-frequency vibrations), and Smells (clinical odors such as eugenol and bonding agents) [12]. Pain and anxiety experienced in dental clinics linger in an individual's memory. Highly anxious children tend to overestimate the pain they will feel in a dental appointment and skip or avoid the dental visit [13].

Behavior modification of disruptive and anxious children through dental visits should happen in a two-step session. Two behavior modifications involve controlling the child during the procedure and teaching the child possible methods to manage dental anxiety [14]. Focusing the child's attention on dental treatment and engaging their cognitive abilities is essential to achieve a positive child-dentist relationship and provide excellent dental care. McElroy, in 1895, famously emphasized behavior as a crucial aspect in pediatric dentistry the notion that although a dental procedure may be perfect, the appointment is a failure if the child departs in tears. Many behavior-guidance techniques are available to reduce a child's fear and anxiety, ranging from basic relaxation techniques to general anesthesia. In 1972, the American Association of Pedodontic Diplomates stated that psychological principles could better manage the troublesome child in a dental clinic, but they were familiar with the use of physical restraints and pharmacological approaches [15]. Complications such as nausea, vomiting, respiratory depression, decreased heart rate, and blood pressure can occur with pharmacological management $[16,17]$.

Non-pharmacological interventions including Tell Show Do (TSD), Modelling, Voice control, Hypnosis, Biofeedback with Guided imagery [18], Distraction with storytelling, Audio [19,20] and Audio-visual aids which target the psychological aspects of the child do not have side-effects and can have better acceptance of the dental treatment by alleviating fear and anxiety [21]. Parents also prefer non-invasive techniques instead of general anesthesia, sedation, restraint, and hand over mouth [14]. During the 1980s, live modeling [22], desensitization [23], and contingency management procedures such as contingent distraction [19], contingent escape, reward [24], and relaxation techniques came into existence to treat disruptive children during dental procedures. Additionally, gentle stroking of the mucosa during the injection with topical anesthesia has proved useful in the field of medicine [25]. Aminabadi et al. found counter-stimulation (CS) helpful in reducing pain during LA administration in children under five years old [26]. Distraction or redirection is believed to work by diverting attention to modulate pain perception. Gate control theory by Melzack and Wall [27] clearly explains the principle behind distraction through the stimulation of the larger diameter type A and type B nerve fibers in a specified area using appropriate pressure or vibration, decreasing the perception of pain by closing a neural gate to nociceptive signals.

Researchers also observed a reduction in dental fear and anxiety with other aids. Filcheck et al. considered videotaped material the best way to modify a child's 


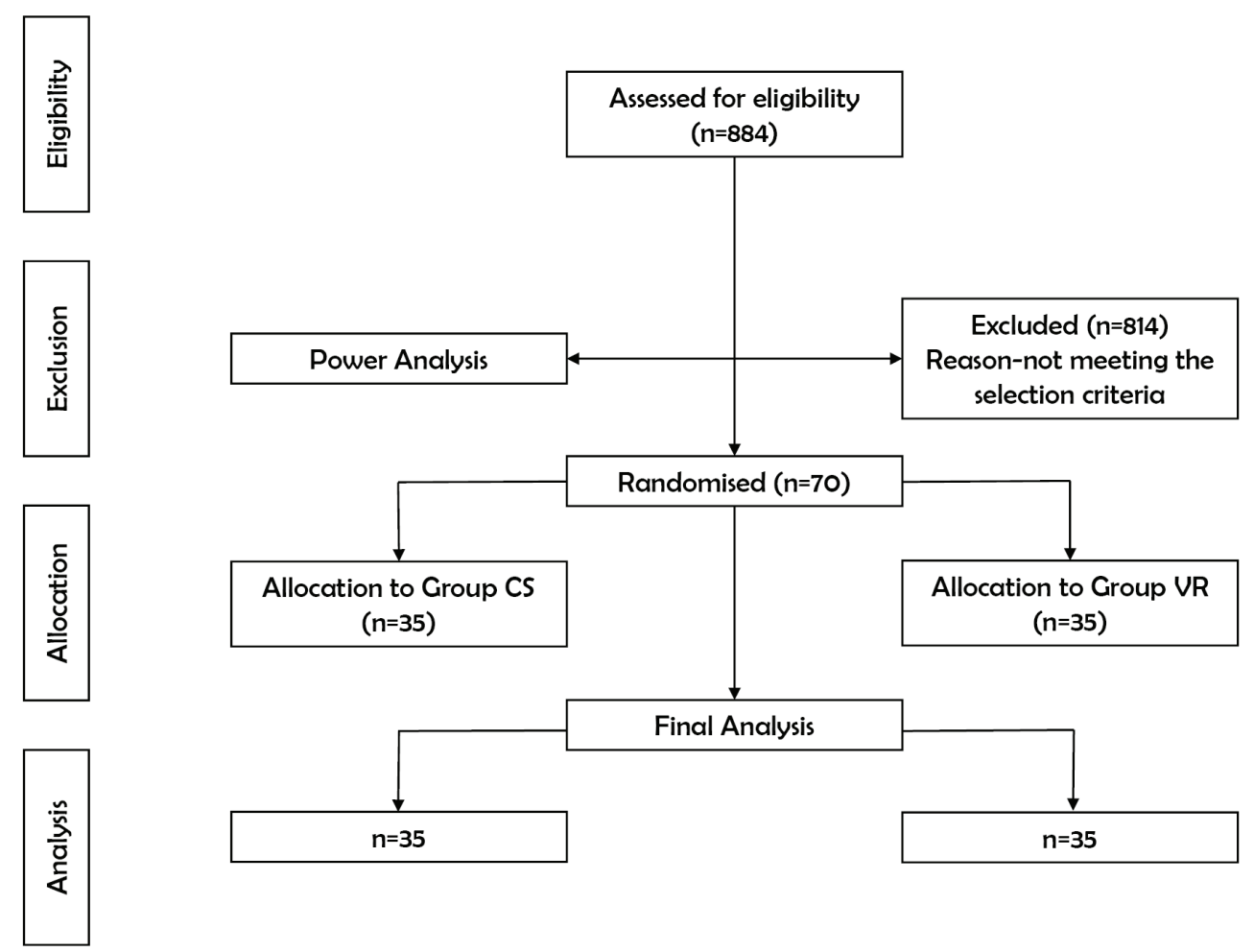

Fig. 1. CONSORT flow diagram of the study design.

behavior in the dental clinic [28]. Ram et al. found that a VR eyeglass system was more efficient than nitrous oxide sedation [29]. In general, parental presence during the dental procedure helps relax the child, but Patel et al. observed higher acceptance to handheld video games than to parents during treatment [30]. Virtual reality (VR) refers to a human-computer interface using 3D headmounted displays with a wide field-of-view. Immersion of the child into a virtual world distracts them from the real world and the pain and stress of dental treatments. VR distraction involves multiple senses such as sight, sound, and kinesthetics to distract from the dental environment socially and emotionally [31, 32]. Studies by Niharika et al. [33], Panda [34], and Agarwal et al. [35] demonstrated that VR distraction could be a better distraction strategy for children with elevated dental fear and anxiety. Based on these studies, CS and VR distraction are potential tools for pain and anxiety alleviation.

Nevertheless, no direct comparisons were made among these two techniques as used in dentistry. Hence, the purpose of the present study was to perform a comparative evaluation of VR and CS distraction and on dental anxiety and pain perception in children's dental procedures. The null hypothesis for the study was that VR is better than CS for reducing dental anxiety.

\section{METHODS}

A prospective, randomized, single-blinded (to the subjects) interventional clinical trial was performed on children attending the Department of Paedodontics and Preventive Dentistry. Ethical clearance was provided by the institutional ethical committee (NDC/IECC/PEDO10-16/41-D168407004) of Narayana Dental College and Hospital. Healthy and anxious children 7-11 years old (positive and negative categories based on Frankl behavior rating scale) [36] who had no prior experience of LA administration were recruited. Children with systemic diseases, special healthcare needs who require pharmacological behavioral guidance techniques were 


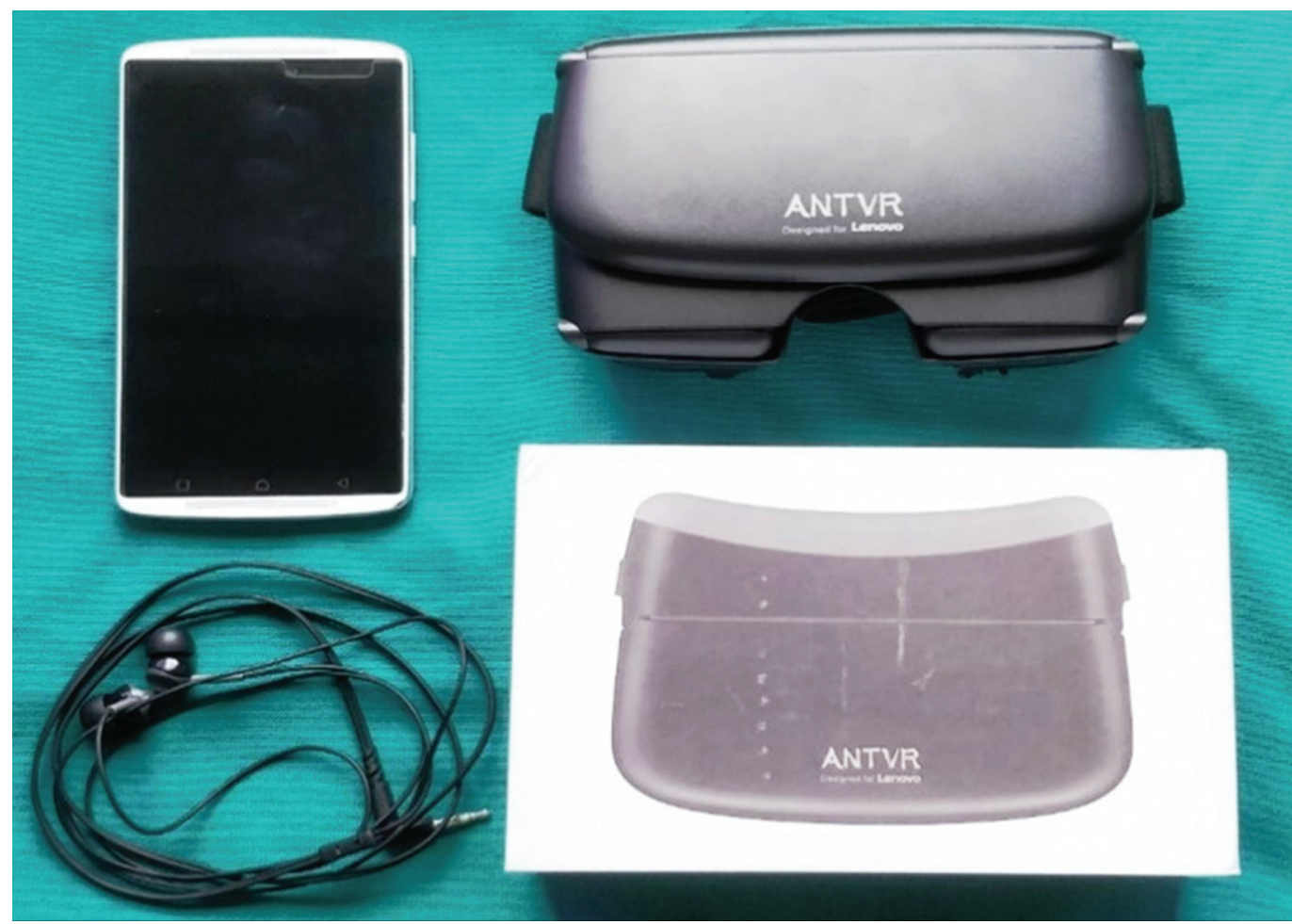

Fig. 2. Materials used for virtual reality distraction (Lenovo smartphone, Sennheiser earphones, and ANTVR glasses).

excluded from participation. Signed informed consent was obtained from the parent or legal guardian of the included children.

A total of 884 children, who visited the Department of Pedodontics and Preventive Dentistry, were initially examined over a four month. Among them, 70 children were selected to participate in the trial, which, confined to the pre-specified selection criteria and power analysis, yielded 35 children per group. Based on random numbers, children $(n=70)$ were sequentially and equally allocated into two groups (CS and VR) of 35 children each (Fig. 1).

ANTVR Phone Glass T2 Designed for Lenovo (model no: PA15LF53A, ANTVR Technology Co., LTD, Beijing, China) enhanced with Theatre Max technology (that can convert any multimedia content into VR) providing a cinematic experience was used in this trial. Its ergonomic design makes it fit on various heads. A distortion-free aspherical lens provides a $100^{\circ}$ field-of-view, and 3D effects immerse the child entirely into the virtual world. A smartphone with cartoons playing on the screen was inserted into foldable arms and mounted on the child's head. ANTVR is economical compared to other VR devices available in the market [37]. Completing the VR set-up was a smartphone (Lenovo Vibe K4 Note, Beijing, China) and earphones (Sennheiser CX 180 Street II (Black), Sennheiser Electronic GmbH \& Co. KG. India) (Fig. 2).

CS is a gentle vibration or stroking of the mucosa adjacent to the site of LA administration using the thumb, with a slight pressure of an equivalent extra-oral site using the forefinger that can reduce pain from an injection. VR distraction is a technique used to divert the child's attention away from the current situation to focus their interest in something else by blocking out real-world (visual, auditory, or both) stimuli, which helps reduce anxiety.

\section{Materials for measuring a child's anxiety}

1. A pulse oximeter to record physiological parameters (Gibson, Fingertip Pulse Oximeter, MD300C29, and Beijing, China). 

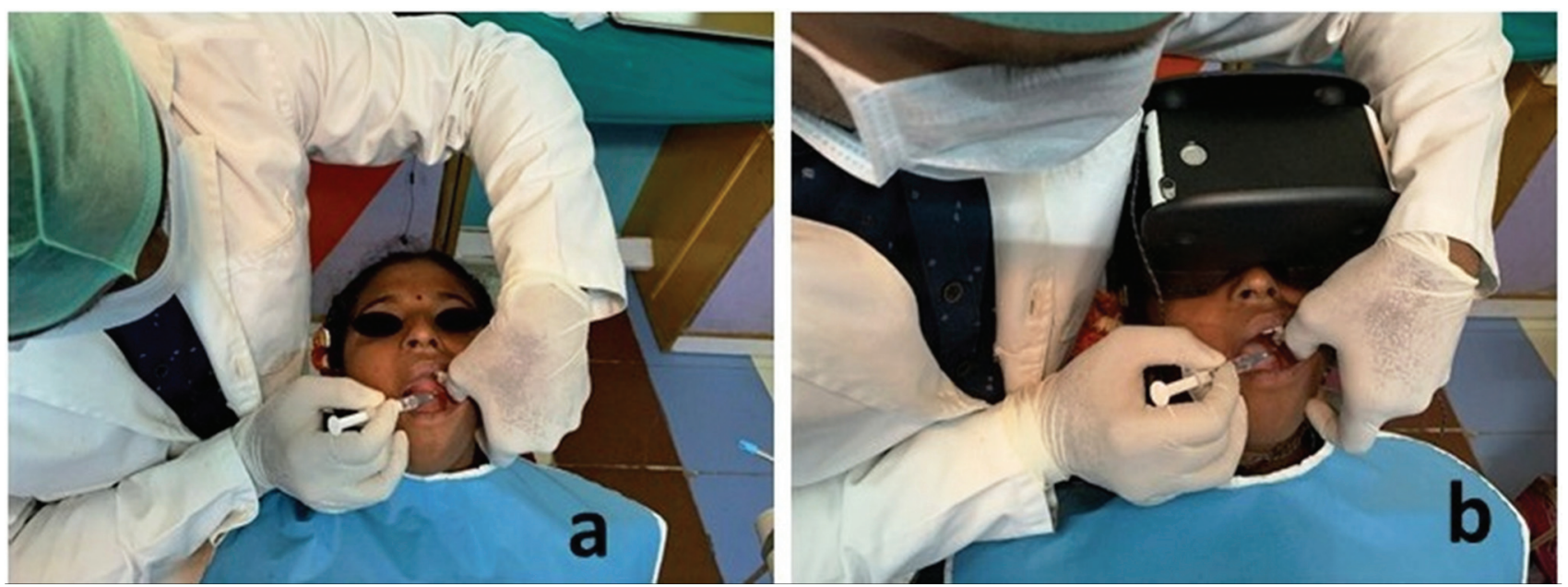

Fig. 3. (a) Stroking the cheek and the extraoral mucosa (Counter-stimulation) and (b) local anesthesia administration with virtual reality distraction.

2. Subjective scales to record self-reporting pain,

a) Wong-Baker Faces Pain Rating Scale (WBFPS)

b) Visual Analogue Scale (VAS).

3. The objective Venham's Clinical Anxiety Rating Scale (VCARS) to record anxiety levels of children

\section{Method of study progression}

Initially, in both groups, anxiety levels were recorded $10 \neg-15$ minutes before local LA administration with a pulse oximeter and Venham's clinical anxiety rating scale. The site of the needle prick was dried with sterile gauze, and topical anesthetic gel $(20 \%$ benzocaine gel; Mucopain, ICPA Health Products Ltd, Mumbai, India) was applied for 30 seconds with a cotton applicator. Anesthetic solution (2\% lidocaine with adrenaline 1:80 000) was injected using a 23-gauge needle at the rate of about $1 \mathrm{~mL} / \mathrm{min}$. In the CS group $(\mathrm{n}=35)$, CS with verbal distraction was performed during LA administration (Fig. 3a) while the children in the VR group (n $=35$ ) watched cartoon videos of their choice from six pre-downloaded locally famous characters in their native language (Fig. 3b). After the LA administration, pain perception to LA was recorded with WBFPS, VAS, and anxiety levels were recorded using pulse oximeter and VCARS. Upon achieving profound anesthesia, standard extraction and pulpectomy procedures were performed.
Table 1. Inter-group comparison of mean values of subjective, objective, and physiologic parameters

\begin{tabular}{|c|c|c|c|c|}
\hline Subjective & Group & Mean & SD & $\mathrm{P}$-value \\
\hline \multirow{2}{*}{ WBFPS } & CS & 2.97 & 2.491 & \multirow{2}{*}{0.770} \\
\hline & VR & 3.03 & 2.022 & \\
\hline \multirow{2}{*}{ VAS } & CS & 3.06 & 2.313 & \multirow{2}{*}{0.991} \\
\hline & VR & 2.94 & 1.765 & \\
\hline \multicolumn{5}{|c|}{ Objective (VCARS) } \\
\hline \multirow{2}{*}{ Before } & CS & 0.63 & 0.942 & \multirow{2}{*}{$0.022^{*}$} \\
\hline & VR & 1.00 & 0.840 & \\
\hline \multirow{2}{*}{ After } & CS & 0.80 & 0.677 & \multirow{2}{*}{0.154} \\
\hline & VR & 0.57 & 0.608 & \\
\hline \multicolumn{5}{|c|}{ Physiologic (PULSE RATE) } \\
\hline \multirow{2}{*}{ Baseline } & CS & 97.15 & 14.914 & \multirow{2}{*}{0.620} \\
\hline & VR & 95.30 & 16.077 & \\
\hline \multirow{2}{*}{ During } & CS & 101.67 & 17.346 & \multirow{2}{*}{$0.032^{*}$} \\
\hline & VR & 93.34 & 14.353 & \\
\hline \multirow{2}{*}{ After } & CS & 100.51 & 15.399 & \multirow{2}{*}{$0.010^{*}$} \\
\hline & VR & 91.56 & 12.679 & \\
\hline
\end{tabular}

${ }^{*} \mathrm{P}<0.05$-statistically significant; virtual reality (VR); counter-stimulation (CS); Wong- Baker Faces Pain Rating Scale (WBFPS); Visual Analog Scale (VAS); Venham's Clinical Anxiety Rating Scale (VCARS); Standard Deviation (SD).

Table 2. Intra-group comparison of mean values of Venham's clinical anxiety rating scale

\begin{tabular}{cccccc}
\hline \multicolumn{2}{c}{ Group } & Mean & SD & Difference & P-value \\
\hline \multirow{2}{*}{ CS } & Before & 0.63 & 0.942 & $0.171 \pm 0.923$ & 0.275 \\
& After & 0.80 & 0.677 & & \\
\hline \multirow{2}{*}{ VR } & Before & 1.00 & 0.840 & $0.429 \pm 0.850$ & $0.008^{*}$ \\
& After & 0.57 & 0.608 & & \\
\hline
\end{tabular}

${ }^{*} \mathrm{P}<0.05$-statistically significant; virtual reality (VR); counter-stimulation (CS); Standard Deviation (SD). 
Table 3. Intra-group comparison between mean values of pulse rate (before versus during), (during versus after), and (before versus after) local anesthesia administration

\begin{tabular}{ccccccccccc}
\hline Group & $\begin{array}{c}\text { Pulse (before) } \\
\text { mean } \pm \text { SD }\end{array}$ & $\begin{array}{c}\text { Pulse (during) } \\
\text { mean } \pm \text { SD }\end{array}$ & P-value & $\begin{array}{c}\text { Pulse (during) } \\
\text { mean } \pm \text { SD }\end{array}$ & $\begin{array}{c}\text { Pulse (after) } \\
\text { mean } \pm \text { SD }\end{array}$ & $\begin{array}{c}\text { P-value } \\
\text { mean } \pm \text { SD }\end{array}$ & $\begin{array}{c}\text { Pulse (before) } \\
\text { mean } \pm \text { SD }\end{array}$ & $\begin{array}{c}\text { (after) } \\
\text { mealue }\end{array}$ \\
\hline CS & $97.15 \pm 14.914$ & $101.67 \pm 17.346$ & $0.024^{*}$ & $101.67 \pm 17.346$ & $100.51 \pm 15.399$ & 0.525 & $97.15 \pm 14.914100 .51 \pm 15.399$ & $0.006^{*}$ \\
VR & $95.30 \pm 16.077$ & $93.34 \pm 14.353$ & 0.235 & $93.34 \pm 14.35391 .56 \pm 12.679$ & 0.198 & $95.30 \pm 16.07791 .56 \pm 12.679$ & $0.030^{*}$ \\
\hline
\end{tabular}

${ }^{*} \mathrm{P}<0.05$-statistically significant; virtual reality (VR); counter-stimulation (CS); Standard Deviation (SD).

Table 4. Mean differences in subjective, objective parameters between boys and girls

\begin{tabular}{ccccccccc}
\hline \multirow{2}{*}{ Gender } & Group & $\begin{array}{c}\text { WBFPS } \\
\text { mean } \pm \text { SD }\end{array}$ & P-value & $\begin{array}{c}\text { VAS } \\
\text { mean } \pm \text { SD }\end{array}$ & P-value & $\begin{array}{c}\text { VCARS (before) } \\
\text { mean } \pm \text { SD }\end{array}$ & $\begin{array}{c}\text { VCARS (after) } \\
\text { mean } \pm \text { SD }\end{array}$ & \begin{tabular}{c} 
P-value \\
\multirow{2}{*}{ Boys }
\end{tabular} \\
& CS & $2.50 \pm 2.00$ & \multirow{2}{*}{0.593} & $3.00 \pm 2.16$ & 0.546 & $0.44 \pm 0.63$ & $0.69 \pm 0.70$ & 0.248 \\
& VR & $2.95 \pm 2.04$ & & $2.63 \pm 1.71$ & & $0.89 \pm 0.88$ & $0.68 \pm 0.67$ & 0.285 \\
\hline \multirow{2}{*}{ Girls } & CS & $3.37 \pm 2.83$ & \multirow{2}{*}{0.959} & $3.11 \pm 2.49$ & \multirow{2}{*}{0.503} & $0.79 \pm 1.13$ & $0.89 \pm 0.66$ & 0.644 \\
& VR & $3.13 \pm 2.06$ & & $3.31 \pm 1.81$ & & $1.13 \pm 0.81$ & $0.44 \pm 0.51$ & $0.008^{*}$ \\
\hline
\end{tabular}

${ }^{*} \mathrm{P}<0.05$-statistically significant; virtual reality (VR); counter-stimulation (CS); Visual Analog Scale (VAS); Venham's Clinical Anxiety Rating Scale (VCARS); Standard Deviation (SD).

\section{Statistical analysis}

Statistical analysis was performed using SPSS (standard statistical, version 17.0 Chicago, USA). The inter-group and intra-group comparisons of WBFPS, VAS, and VCARS were made using a chi-square test and unpaired t-test, respectively. The continuous variations in pulse were tested with repeated measure ANOVA. P-values less than 0.05 were considered as statistically significant.

\section{RESULTS}

There were 70 participants with almost equal gender distribution in both groups (CS, $45.7 \%$ boys, $54.3 \%$ girls; VR $54.3 \%$ boys, $45.7 \%$ girls). The mean age and standard deviation (SD) for the CS and VR groups were $8.80 \pm$ 1.389 and $8.91 \pm 1.442$, respectively. The number of extractions was $48.6 \%$ in the CS group, and $57.1 \%$ in the VR group, whereas $51.4 \%$ (CS) and $42.9 \%$ (VR) were pulp therapies completed in the primary mandibular molars. There was no significant difference between groups among age, gender, type of treatment performed.

Inter-group comparison between mean values of self-reported pain during LA administration (WBFPS, $\mathrm{P}$ $=0.770 ;$ VAS, $\mathrm{P}=0.0991)$ were not statistically significant. The objective parameter VCARS recorded before LA administration ( $\mathrm{P}=0.022)$ was statistically significant in both the groups but not the VCARS after the procedure $(\mathrm{P}=0.154)$. A comparison between mean values of the physiologic measure (pulse rate) during ( $\mathrm{P}$ $=0.032)$ and after $(\mathrm{P}=0.010) \mathrm{LA}$ administration was statistically significant. Pulse rates at baseline showed no absolute difference between the two groups (Table 1).

A statistical difference $(\mathrm{P}=0.008)$ in mean VCARS scores was observed in the VR group before and after LA administration whereas, in the CS group, there were no differences ( $P=0.275)$ witnessed (Table 2$)$. In both groups, a decrease in pulse rates was observed after LA administration with the interventions (CS and VR), and the VR group had a significantly higher reduction in pulse rate (Table 3 ).

In both of the groups, mean differences in subjective parameters between boys and girls were not statistically significant $(\mathrm{P}>0.05)$, but objective assessment (VCARS) of mean anxiety scores showed a significant difference $(\mathrm{P}=0.008)$ in girls of the VR group (Table 4). The post-intervention pulse rate reduction was significant in girls, and a significant decrease $(\mathrm{P}<0.001)$ in pulse rates 
Table 5. Mean differences in pulse rates between boys and girls

\begin{tabular}{|c|c|c|c|c|c|c|c|c|c|c|}
\hline Sex & Group & $\begin{array}{c}\text { Pulse (before) } \\
\text { mean } \pm \text { SD }\end{array}$ & $\begin{array}{l}\text { Pulse (during) } \\
\text { mean } \pm \text { SD }\end{array}$ & P-value & $\begin{array}{l}\text { Pulse (during) } \\
\text { mean } \pm \text { SD }\end{array}$ & $\begin{array}{l}\text { Pulse (after) } \\
\text { mean } \pm \text { SD }\end{array}$ & P-value & $\begin{array}{c}\text { Pulse (before) } \\
\text { mean } \pm \text { SD }\end{array}$ & $\begin{array}{l}\text { Pulse (after) } \\
\text { mean } \pm \text { SD }\end{array}$ & P-value \\
\hline \multirow{2}{*}{ Boys } & CS & $95.92 \pm 15.33$ & $97.98 \pm 16.12$ & 0.485 & $97.98 \pm 16.12$ & $96.47 \pm 15.97$ & 0.653 & $95.92 \pm 15.33$ & $96.47 \pm 15.97$ & 0.759 \\
\hline & VR & $94.19 \pm 15.07$ & $92.03 \pm 14.02$ & 0.339 & $92.03 \pm 14.02$ & $91.11 \pm 13.16$ & 0.600 & $94.19 \pm 15.07$ & $91.11 \pm 13.16$ & 0.248 \\
\hline \multirow{2}{*}{ Girls } & CS & $98.18 \pm 14.90$ & $104.77 \pm 18.15$ & $0.018^{*}$ & $104.77 \pm 18.15$ & $103.90 \pm 14.45$ & 0.659 & $98.18 \pm 14.90$ & $103.90 \pm 14.45$ & $<0.001^{*}$ \\
\hline & VR & $96.63 \pm 17.60$ & $94.90 \pm 15.05$ & 0.498 & $94.90 \pm 15.05$ & $92.08 \pm 12.49$ & 0.220 & $96.63 \pm 17.60$ & $92.08 \pm 12.49$ & $0.040^{*}$ \\
\hline
\end{tabular}

${ }^{*} \mathrm{P}<0.05$-statistically significant; virtual reality (VR) counter-stimulation (CS); Standard Deviation (SD).

was observed in girls of the CS group (Table 5).

\section{DISCUSSION}

Dental fear and anxiety in children may be due to unknown stimuli or due to the negative influence of parents who have had unpleasant dental experiences [38]. Dental anxiety is a multi-dimensional model that contains social, perceptive, and physiological components, use of a single parameter to quantity it may not yield an accurate result [39]. Therefore, a combination of two subjective scales (to self-report of pain after LA); WBFPS [40] and VAS [41] one objective scale; VCARS [42] and a physiologic measure (pulse rate) were used to measure pain and anxiety in children because a single parameter cannot provide an accurate assessment because the thresholds of pain perception may differ for each child.

Aitken conveyed that a self-reported assessment of pain provides an immediate state of emotional feeling towards dental treatment and is usually based on verbal communication with the patient [43]. The WBFPS used in the present study proved to be extremely sensitive in the subjective assessment of pain in children during dental procedures [44]. The VAS was introduced by Aitken [43], and initially, it was used to measure the psychological states of patients. Later Ohnhaus [45] calculated pain intensities using VAS. In dentistry, its first use dates to 1988 as a simple tool to assess subjective parameters. Previous studies validated and recommended its use to evaluate anxiety [46] and pain [13] in a dental setting. VCARS [42] is a six-point interval rating scale used to measure the situational anxiety of the child and is reliable, valid, and can be easily integrated into clinical or research activities [21]. Pulse rate increase during dental treatments is attributed to stressful situations. Measurement using fingertip pulse oximeter is useful because of the direct measure of physiological arousal [47].

The study included 70 children ( 35 males, 35 females) with equal numbers of children allocated to two intervention groups. Children with no previous experience of LA were selected because it is proven that pain perception to LA is influenced by the order of injection. Martin et al. found in 1994 that the second injection was more perceived as more painful compared to the first injection [48]. In children, invasive procedures involving LA injection will always be challenging because the fear imagined by the child is related to their level of pain perception and uncooperative behavior [49].

For decades dentists have used various behavior guidance techniques to reduce the children's anxiety to LA injection, including non-pharmacological and pharmacological types (general anesthesia and conscious sedation) [50]. According to McCaul and Mallot [51], distracting the child from an unpleasant stimulus can result in decreased pain perception. Counter stimulation and VR methods were used in the present study to reduce the pain and anxiety to LA injection during extraction and pulp therapies.

CS of the extra-oral site equivalent to the exact intra-oral injection site helped in reducing the child's pain perception, and anxiety as the sensory vibration reflexes produced by extra-oral stimulation reaches the brain before the pain does. The proper distribution of LA is noted with the intra-oral stroking of mucosa with the thumb. We found a significant reduction in the 
physiological parameter (pulse rates) in the CS group after the LA administration, but anxiety levels with VCARS were not statistically significant. Mean pain scores calculated with VAS in the CS group were less compared to the VR group, but no meaningful change could be noticed with mean WBFPS scores. A similar study by Aminabadi et al. compared CS combined with verbal distraction with $\mathrm{CS}$ alone and conventional methods of LA administration in five year-old children and found that pain perception was less in children who received CS and verbal distraction [26].

VR uses fantasy worlds, and 3D virtual real-life situations with high ecological validity are more acceptable to the children. McCaffery and Pasero [52] have explained sensory shielding, the mechanism in which the child protected from the pain stimulus by the increased sensory input from the virtual reality distractors. Many studies using VR distraction being carried out with positive outcomes.

In a recent randomized trial of 400 children by Khandelwal et al., it was found that audio-visual distraction is superior to TSD in managing $5-\neg-8$-year old anxious children [53]. Coinciding with this, we witnessed a significant reduction in mean pulse rates in children who had their injection while watching cartoons under VR distraction (ANTVR eyeglasses). Amal Khotani et al. concluded that VR distraction with i-theatreTM eyeglasses reduced observer-rated dental anxiety in eight year-old children during restorative dental treatment [54]. It was shown that VR distraction is also useful in children with learning disabilities, reducing dental anxiety in 28 children with Autism Spectrum Disorder while performing oral prophylaxis and sealant application [55]. Children are very fond of smartphone gaming. Shah et al., through a cross-over randomized trial, concluded that pre-procedural gaming resulted in a significant difference in hemodynamic parameters of 60 children between $5 \neg$ and 10 years old [56]. This study found that girls showed a more significant reduction in anxiety than boys. These findings are similar to Amal Khotani et al. [54], but Nuvvula et al. [57] found no significant difference in anxiety between both boys and girls.

Results of the present study are remarkably close to the randomized trial by Aminabadi et al. [58] though the number of children $(n=120)$ and their ages $(4-6$ years) differed. A self-reported measure of pain during LA administration with WBFPS was less in the children using VR in both studies. Concurring with those results, Agarwal [35] and EL Sharkawi [59] reported pain reduction during topical anesthetic application and LA with the use of audiovisual distraction. In addition, few researchers found adverse effects of audiovisual distraction concerning pain experience during dental visits of children [60-62]. Pain during LA was less in the VR group measured with VAS, as also observed by Agarwal, and coincides with our mean VAS scores, which showed less pain in the VR group compared to the CS group [35].

Aminabadi et al. [58] and Nuvvula et al. [57] noticed anxiety reduction in dental-phobic children with the use of audiovisual aids during their course of dental treatment measured with the faces version of the modified child dental anxiety scale MCDAS which was also previously reported by several studies. Likewise, in the current study, a significant reduction in the anxiety levels was observed, but the scale used was VCARS. Interestingly, Sullivan et al. found that VR distraction was ineffective for decreasing anxiety levels in children undergoing invasive dental procedures [63]. Physiological assessment of pulse rate with pulse oximeter showed a positive correlation between the mean scores calculated before, during, and after the distraction with ANTVR eyeglasses in the present clinical trial. Studies by Sullivan et al. [63], Mitrakul [60], and Agarwal [35] had comparable results. Contradicting this, Nuvvula et al. [57] and Al Khotani [54] found no significant difference in the pulse rates between the audiovisual and control groups.

A recent systematic review by Liu et al. [64] found low-quality evidence suggesting that the usage of audiovisual distraction during dental treatment. ANTVR, a VR headset with the required features, when compared 
to other previously used eyeglasses in studies by Aminabadi et al. [44], Nuvvula et al. [57] and Niharika et al. [33] is better economically and is more available. The strengths of the current study are that VR distraction has not been compared to CS in earlier research, and the ANTVR headset used is exceptionally cost-effective. The small number of participants is a limitation of the present clinical study. From the above observations, the following conclusions can be drawn,

1) VR distraction is a more useful behavior guidance modality to decrease dental fear and anxiety in children during LA administration compared to CS.

2) Not confined to LA administration, most of the children in the VR group wished to continue watching cartoons in the VR headset throughout their treatment period as it blocked the sight and sounds of dental instruments.

3) The ANTVR headset is cost-effective and readily available compared to other VR distraction devices.

\section{AUHHOR OREIDS}

Rupak Kumar Dasaraju: https://orcid.org/0000-0002-8820-941X Rekhalakshmi Kamatham: https://orcid.org/0000-0002-5715-4620 Sreekanth Kumar Mallineni: https://orcid.org/0000-0002-9432-2590 Sivakumar Nuvvula: https://orcid.org/0000-0002-1204-5551

ACKNOWLEDGMENTS: Thanks to children and parents who participated in the present study

DECLARATION OF INTEREST: The authors declare no conflict of interest

FUNDING: The authors received no financial support for the research, authorship, or publication of this article.

\section{REFERENCES}

1. Pain terms: a list with definitions and notes on usage: Recommended by IASP subcommittee on Taxonomy. Pain 1979; 6: 249.

2. Nomura LH, Bastos JL, Peres MA. Dental pain prevalence and association with dental caries and socioeconomic status in school-children, Southern Brazil, 2002. Braz Oral Res 2004; 18: 134-40.

3. Bedi R, Sutcliffe P, Donnan PT, McConnachie J. The prevalence of dental anxiety in a group of 13- and 14-year-old Scottish children. Int J Pediatr Dent 1992; 2: $17-24$.

4. Klingberg G, Broberg AG. Dental fear/anxiety and dental behaviour management problems in children and adolescents: a review of prevalence and concomitant psychological factors. Int J Pediatr Dent 2007; 17: 391-406.

5. Kaur R, Jindal R, Dua R, Mahajan S, Sethi K, Garg S. Comparative evaluation of the effectiveness of audio and audiovisual distraction aids in the management of anxious pediatric dental patients. J Indian Soc Pedod Prev Dent 2015; 33: 192-203.

6. Folayan MO, Fatusi A. Effect of psychological management techniques on specific item score change during the management of dental fear in children. J Clin Pediatr Dent 2005; 29: 335-40.

7. Corah NL, Gale EN, Illig SJ. Psychological stress reduction during dental procedures. J Dent Res 1979; 58: 1347-51.

8. Agarwal M, Das UM. Dental anxiety prediction using Venham Picture test: A preliminary cross- sectional study. J Indian Soc Pedod Prev Dent 2013; 31: 22-4.

9. Agras S, Sylvester D, Oliveau D. The epidemiology of common fears and phobia. Compr Psychiatry 1969; 10: 151-6.

10. Rachman S. The conditioning theory of fear acquisition: a critical examination. Behav Res Ther 1977; 15: 375-87.

11. Carrillo-Diaz M, Crego A, Armfield JM, Romero-Maroto M. Assessing the relative efficacy of cognitive and non-cognitive factors as predictors of dental anxiety. Eur J Oral Sci 2012; 120: 82-8.

12. Hmud R, Walsh LJ. Dental anxiety: causes, complications and management approaches. J Minim Interv Dent 2009; 2: $67-78$

13. Kent G. Cognitive processes in dental anxiety. Br J Clin Psychol 1985; 24: 259-64.

14. Allen KD, Stanley RT, McPherson K. Evaluation of behaviour management technology dissemination in 
pediatric dentistry. Pediatr Dent 1990; 12: 79-82

15. Technique for behavior management--a survey. The Association of Pedodontic Diplomates. ASDC J Dent Child 1972; 39: 368-72.

16. Chow CH, Van Lieshout RJ, Schmidt LA, Dobson KG, Buckley N. Systematic review: audiovisual interventions for reducing preoperative anxiety in children undergoing elective surgery. J Pediatr Psychol 2016; 41: 182-203.

17. Xiaolian J, Xiaolin L, Lan ZH. Effects of visual and audiovisual distraction on pain and anxiety among patients undergoing colonoscopy. Gastroenterol Nurs 2015; 38: 5561.

18. Dedeepya P, Nuvvula S, Kamatham R, Nirmala SV. Behavioural and physiological outcomes of biofeedback therapy on dental anxiety of children undergoing restorations: a randomised controlled trial. Eur Arch Paediar Dent 2014; 15: 97-103.

19. Ingersoll BD, Nash DA, Gamber C. The use of contingent audiotaped material with pediatric dental patients. J Am Dent Assoc 1984; 109: 717-9.

20. Stark LJ, Allen KD, Hurst M, Nash DA, Rigney B, Stokes TF. Distraction: its utilization and efficacy with children undergoing dental treatment. J Appl Behav Anal 1989; 22: $297-307$.

21. Navit S, Johri N, Khan SA, Singh RK, Chandha D, Navit $\mathrm{P}$, et al. Effectiveness and comparison of various audio distraction aids in management of anxious dental Pediatric patients. J Clin Diagn Res 2015; 9: 5-9.

22. Williams JA, Hurst MK, and Stokes TF. Peer observation in decreasing uncooperative behavior in young dental patients. Behav Modif 1983; 7: 225-42.

23. Klesges RC, Malott JM, Ugland M. The effects of graded exposure and parental modeling on the dental phobias of a four year old girl and her mother. J Behav Ther Exp Psychiatry 1984; 15: 161-4.

24. Allen KD, Stokes TF. The use of escape and reward in the management of young children during dental treatment. J Appl Behav Anal 1987; 20: 381-90.

25. Willis WD, Coggeshall RE. Sensory mechanism of the spinal cord. 2nd ed. New York, Plenum Press, 1991.

26. Aminabadi NA, Farahani RM, Balayi Gajan E. The efficacy of distraction and counterstimulation in the reduction of pain reaction to intraoral injection by pediatric patients. J Contemp Dent Pract 2008; 9: 33-40.

27. Melzack R, Wall PD. Pain mechanisms: a new theory. Science 1965; 150: 971-9.

28. Filcheck HA, Allen KD, Ogren H, Darby JB, Holstein B, Hupp S. The use of choice-based distraction to decrease the distress of children at the dentist. Child Fam Behav Ther 2004; 26: 59-68.

29. Ram D, Shapira J, Holan G, Magora F, Cohen S, Davidoch E. Audiovisual video eyeglass distraction during dental treatment in children. Quintessence Int 2010; 41: 673-9.

30. Patel A, Schieble T, Davidson M, Tran MC, Schoenberg C, Delphin E, et al. Distraction with a handheld video game reduces pediatric preoperative anxiety. Pediatr Anaesth 2006; 16: 1019-27.

31. Wismeijer AA, Vingerhoets AJ. The use of virtual reality and audiovisual eyeglasses system as adjunct analgesic techniques: a review of the literature. Ann Behav Med 2005; 30: 268-78.

32. Slifer KJ, Tucker CL, Dahlquist LM. Helping children and caregivers cope with repeated invasive procedures: how are we doing? J Clin Psychol 2002; 9: 131-52.

33. Niharika P, Reddy NV, Srujana P, Srikanth K, Daneswari V, Geetha KS. Effects of distraction using virtual reality technology on pain perception and anxiety levels in children during pulp therapy of primary molars. J Indian Soc Pedod Prev Dent 2018; 36: 364-9.

34. Panda A. Effect of virtual reality distraction on pain perception during dental treatment in children. Int J Oral Res 2017; 5: 278-81.

35. Agarwal N, Dhawan J, Kumar D, Anand A, Tangri K. Effectiveness of two topical anaesthetic agents used along with audio visual aids in pediatric dental patients. J Clin Diagn Res 2017; 11: 80-3.

36. American Academy Pediatric Dentistry. Reference manual guideline on behavior guidance for the pediatric dental patient. Pediatr Dent 2015; 37: 182-93.

37. ANTVR. http://antvr.com/en/ANTVR_PhoneGlassE. html.

38. Bare LC, Dundes L. Strategies for combating dental 
anxiety. J Dent Educ 2004; 68: 1172-7.

39. Aartman IH, van Everdingen T, Hoogstraten J, Schuurs AH. Self-report measurements of dental anxiety and fear in children: a critical assessment. ASDC J Dent Child 1998; 65: $252-8$.

40. Wong DL, Baker CM. Pain in children: comparison of assessment scales. Pediatric Nursing 1988; 14: 9-17.

41. Powell CV, Kelly AM, Williams A. Determining the minimum clinically significant difference in visual analog pain score for children. Ann Emerg Med 2001; 37: 28-31.

42. Venham LL, Gaulin-Kremer E, Munster E, BengstonAudia D, Cohan J. Interval rating scales for children's dental anxiety and uncooperative behavior. Pediatr Dent 1980; 2: 195-202.

43. Aitken RC. A growing edge of measurement of feelings measurement of feelings using visual analogue scales. Proc Roy Soc Med 1969; 62: 989-93

44. Khatri A, Kalra N. A comparison of two pain scales in the assessment of dental pain in East Delhi children. ISRN Dent 2012; 2012: 247351.

45. Ohnhaus EE and Alder R. Methodological problems in the measurement of pain. A comparison between the verbal rating scale and the visual analogue scale. Pain 1975; 1: 379-84.

46. Luyk NH, Beck FM, Weaver JM. A visual analogue scale in the assessment of dental anxiety. Anesth Prog 1988; 35: $121-3$.

47. Yelderman M, New W Jr. Evaluation of pulse oximetry. Anesthesiology 1983; 59: 349-52.

48. Martin MD, Ramsay DS, Whitney C, Fiset L, Weinstein P. Topical anesthesia: Differentiating the pharmacological and psychological contributions to efficacy. Anesth Prog 1994; 41: 40-7.

49. Bankole OO, Aderinokun GA, Denloye OO, Jeboda SO. Maternal and child's anxiety-effect on child's behaviour at dental appointments and treatments. Afr J Med Med Sci 2002; 31: 349-52.

50. Cianetti S, Paglia L, Gatto R, Montedori A, Lupatelli E. Evidence of pharmacological and non-pharmacological interventions for the management of dental fear in Pediatric dentistry: a systematic review protocol. BMJ Open 2017;
7: e016043.

51. McCaul KD, Malott JM. Distraction and coping with pain. Psychol Bull 1984; 95: 516-33.

52. Caffery Mc, Pasero C. Pain: Clinical Manual, 2nd ed. St. Louis, MO: Mosby: 1999; 399-427.

53. Khandelwal D, Kalra N, Tyagi R, Khatri A, Gupta K. Control of anxiety in pediatric patients using "Tell Show Do" method and audiovisual distraction. J Contemp Dent Pract 2018; 19: 1058-64.

54. Al-Khotani A, Bello LA, Christidis N. Effects of audiovisual distraction on children's behaviour during dental treatment: a randomised controlled clinical trial. Acta Odontol Scand 2016; 74: 494-501.

55. Fakhruddin KS, El Batawi HY. Effectiveness of audiovisual distraction in behavior modification during dental caries assessment and sealant placement in children with autism spectrum disorder. Dent Res J 2017; 14: 177-82.

56. Shah HA, Nanjunda Swamy KV, Kulkarni S, Choubey S. Evaluation of dental anxiety and hemodynamic changes (Sympatho-Adrenal Response) during various dental procedures using smartphone applications $\mathrm{v} / \mathrm{s}$ traditional behaviour management techniques in pediatric patients. Int J Adv Res 2017; 3: 429-33.

57. Nuvvula S, Alahari S, Kamatham R, Challa RR. Effect of audiovisual distraction with 3D video glasses on dental anxiety of children experiencing administration of local analgesia: a randomised clinical trial. Eur Arch Pediatr Dent 2015; 16: 43-50.

58. Asl Aminabadi N, Erfanparast L, Sohrabi A, Ghertasi Oskouei S, Naghili A. The impact of virtual reality distraction on pain and anxiety during dental treatment in 4-6 year-old children: a randomised controlled clinical trial. J Dent Res Dent Clin Dent Prospect 2012; 6: 117-24.

59. EI-Sharkawi HF, EI-Housseiny AA, Aly AM. Effectiveness of new distraction technique on pain associated with injection of local anesthesia for children. Pediatr Dent 2012; 34: $35-8$.

60. Mitrakul K, Asvanund Y, Arunakul M, Paka-akaekaphat S. Effect of audiovisual eyeglasses during dental treatment in 5-8 yearold children. Eur J Pediatr Dent 2015; 16: 23945. 
61. Fakhruddin KS, El Batawi H, Gorduysus MO. Effectiveness of audiovisual distraction eyewear and computerized delivery of anesthesia during pulp therapy of primary molars in phobic child patients. Eur J Dent 2015; 9: 470-5.

62. Hoge MA, Howard MR, Wallace DP, Allen KD. Use of video eyewear to manage distress in children during restorative dental treatment. Pediatr Dent 2012; 34: 378-82.

63. Sullivan C, Schneider PE, Musselman RJ, Dummett CO,
Gardiner D. The effect of virtual reality during dental treatment on child anxiety and behavior. ASDC J Dent Child 2000; 67: 193-6, 160-1.

64. Liu Y, Gu Z, Wang Y, Wu Q, Chen V, Xu X, et al. Effect of audiovisual distraction on the management of dental anxiety in children: A systematic review. Int J Pediatr Dent 2019; 29: 14-21. 